\title{
The influence of task difficulty and external tempo on subjective time estimation
}

\author{
DAN ZAKAY, DEVORA NITZAN, and JOSEPH GLICKSOHN \\ Tel-Aviv University, Ramat Aviv, Israel
}

\begin{abstract}
Ninety-six subjects were asked to estimate durations of either "empty" or "filled" intervals during which they performed verbal tasks at three levels of difficulty. The verbal tasks were performed under three conditions of external rhythmic stimulation: fast, slow, and no external tempo. It was found that subjective time estimations were a decreasing function of task difficulty, and that durations for "empty" intervals were estimated to be longer than those for "filled" intervals. A relationship between external tempo and subjective time estimation was found. Longest time estimates were obtained under fast external tempo, and shortest time estimates were obtained under slow external tempo. Time estimates under the condition of no external tempo were found to be intermediate. The findings were interpreted as supporting a cognitive timer model of subjective time estimation.
\end{abstract}

The influence of concurrent information processing on subjective time estimation (STE) has been investigated in a large number of studies. These have encompassed a wide range of objective time intervals, within which subjects have been actively, and continuously, engaged in tasks demanding information processing (e.g., card sorting, reading, word copying, arithmetic, Stroop color-word tasks, etc.). In most of these studies (e.g., Burnside, 1971; Curton \& Lordahl, 1974; Devane, 1974; Fraisse, 1963; Gulliksen, 1927; Hicks, Miller, Gaes, \& Bierman, 1977; Hicks, Miller, \& Kinsbourne, 1976; Swift \& McGough, 1925; Vroon, 1970; Zakay \& Fallach, in press), it has consistently been found that STE is: (1) an inverse function of processing load or task difficulty, and (2) positively related to the number of responses, or amount of information-processing output. However, in some studies (e.g., Avant, Lyman, \& Antes, 1975; Block, 1978; Lyman \& Avant, 1975; Michon, 1965; Ornstein, 1969), time estimates were found to be a positive function of processing load.

Two different models have been proposed in the literature to explain these results, each pertaining mainly to one of these two trends of results:

(1) The storage-size model of Ornstein (1969), according to which STE is dependent on the amount of information stored in memory due to concurrent information processing. This model is supported by the findings in which a positive relationship between STE and processing load was obtained, but is refuted by findings that present an inverse relation between task difficulty or processing load and STE. In order to accommodate the storage-size model with findings showing a positive relationship between STE and

The author's mailing address is: Department of Psychology, Tel-Aviv University, Ramat Aviv 69978, Israel. amount of response or output, one has to assume a direct relationship between amount of output and storage size (Burnside, 1971). However, this assumption does not hold for all conditions, for one may need to consider a task having a high processing load but a small output, such as in problem solving.

(2) The attentional model of Frankenhauser (1959) and Priestly (1968), according to which STE is a direct function of the amount of attention that is allocated to the passage of time. It is assumed here that there exists a cognitive unit (timer) whose purpose is to process and encode temporal information, utilizing attentional resources for this function. As nontemporal information load is reduced, more attentional resources may be allocated to the cognitive timer, whose storage of temporal information is thus increased, resulting in a longer STE. Therefore, this attentional model is supported by the findings that show that an increase in task difficulty results in a shorter STE. Another type of finding that has been consistently found in regard to intervals of objective durations longer than $1 \mathrm{sec}$ is that an "empty" interval is judged to be longer than a "filled" one, that is, an interval filled with a sensory stimulus or one in which the subject is involved in some sort of task demanding information processing (e.g., Burnside, 1971; Gulliksen, 1927; Hicks et al., 1976; McKay \& Timothy, 1977). This last finding supports the attentional model and refutes the storage-size model. As for the direct relationship between STE and number of responses, it is easily explained by the attentional model through task difficulty, since number of responses per unit of time should be a negative function of task difficulty and so is STE. Thus, a positive relationship between STE and number of responses is expected.

On the basis of all the above-mentioned findings, it 
seems that the attentional model is supported more fully and consistently than the storage-size model.

Another factor whose influence on STE was investigated is that of environmental stimulation not directly related to the task performed during the target interval. However, the results are not clear-cut. Aitken and Gedye (1968) found that STE was longer given a noisy environment. In contrast, Hawkes, Bailey, and Warm (1961) did not find any effect for noise or cutaneous stimulation on STE. As for the effect of the rate of environmental stimulation or bodily activity, the accepted hypothesis is of a direct relationship between autonomic, actional or perceptual tempo, and STE. Both Frankenhauser (1959) and Ornstein (1969) found that STE was longer with the increasing beat of a metronome. Denner, Wapner, McFarland, and Werner (1963) reported that STE was longer with fast, rhythmic bodily activity. These findings might be explained in terms of either the storage-size model or the cognitive timer model. According to the storage-size model, a faster external stimulation, which is equivalent to more stimulation per unit of objective time, increases the amount of information processed and stored, and hence STEs associated with a high rate of external stimulation should be longer than those associated with a low rate of external stimulation. This explanation, however, is not consistent with the attentional model, because if a positive relationship exists between rate of nonrelevant external stimulation and information processing load, then a negative relationship between external stimulation rate and length of STE should be expected, which is not the case. However, if one assumes the existence of a separate temporal information-processing unit, then one may propose that the rate of its functioning is determined by both psychological and physiological factors (Hoagland, 1935; Hawkes, Joy, \& Evans, 1962; Hawkes \& Worsham, 1970). The cognitive timer might be considered as being a psychobiological clock that can speed up or slow down, depending on external as well as internal conditions. Schiffman (1976) suggests that "the possession of a biological mechanism that varies bodily functions to certain temporally related environmental events offers a biological advantage to the organism, in that the internal rhythms react adaptively to periodic change in the environment" (p. 353). Accordingly, it is proposed here that the cognitive timer is activated by the focusing of attention on temporal information and, in addition, operates according to some internal rate. The higher that rate, the shorter the subjective time unit and the more time units are registered whenever the timer is activated. Hence, when nonrelevant external rhythmic stimulation exists, the faster the stimulation, (1) the more attention is paid to temporal information because of the temporal meaning assigned to rhythmic stimulation, and (2) the more the cognitive timer speeds up and the greater are the number of subjective units registered whenever it is activated. [This hypothesis, however, should be treated very cautiously in light of the fact that empirical research has been unsuccessful in demonstrating a change in the rate of the internal timer, research that was concluded by Schiffman (1976) to raise mixed evidence and results that were difficult to interpret.] The opposite is the case in regard to slow external rhythmic stimulation. Hence, a positive relationship between rate of external tempo and length of STE is predicted on the basis of the cognitive timer model.

The factors of task difficulty, rate of nonrelevant external tempo, number of responses, and STE have so far been investigated in various combinations and in different studies. Hicks et al. $(1976,1977)$ point to the methodological problems that are involved in STE research which render implausible a direct comparison of results obtained by different methods of time estimation and in regard to different objective durations. The purpose of the present study was therefore to investigate the interaction between these variables so that by the pattern of results obtained it would be possible to lend support to either the storage-size model or the timer model.

According to the storage-size model, one would expect: (1) a positive relationship between task difficulty and length of STE, (2) a shorter STE for "empty" intervals than for "filled" ones, (3) a positive relationship between number of responses and length of STE, and (4) a positive relationship between rate of nonrelevant external tempo and length of STE.

According to the timer model, one would expect: (1) a negative relationship between task difficulty and length of STE, (2) a longer STE for "empty" intervals than for "filled" ones, and (3) a positive relationship between rate of nonrelevant external tempo and length of STE. No specific relationship was predicted between number of responses and STE, but, for the sake of consistency, a negative relationship between number of responses and task difficulty was expected.

It should be stressed that, since the predictions about the relationship between external tempo and STE are identical for both models, the real test was in the internal consistency of all the predictions. A set of results inconsistent with either of the two models would prevent supporting either of them.

\section{METHOD}

\section{Subjects \\ Ninety-six students (48 males and 48 females), whose average age was 25 years, participated in the experiment in partial ful- fillment of the requirements of a first-year introductory psy- chology class.}

\section{Apparatus and Stimuli}

The concurrent task was a verbal one with three levels of difficulty: (1) easy level, reading words (W); (2) intermediate level, naming task $(\mathrm{N})$; and (3) difficult level, providing synonyms for 
Table 1

Experimental Design

\begin{tabular}{|c|c|c|c|c|c|}
\hline \multirow[b]{3}{*}{ Task } & \multicolumn{4}{|c|}{ External Tempo } & \multirow{3}{*}{$\begin{array}{c}\text { No ET } \\
\text { (Control) }\end{array}$} \\
\hline & \multicolumn{2}{|c|}{ Fast } & \multicolumn{2}{|c|}{ Slow } & \\
\hline & V & A & V & $\mathbf{A}$ & \\
\hline W & FVW & FAW & SVW & SAW & $\mathrm{CW}$ \\
\hline $\mathbf{N}$ & FVN & FAN & SVN & SAN & $\mathrm{CN}$ \\
\hline$S$ & FVS & FAS & SVS & SAS & $\mathrm{CS}$ \\
\hline E & FVE & FAE & SVE & SAE & $\mathrm{CE}$ \\
\hline
\end{tabular}

Note $-V=$ visual $; A=$ auditory $; E T=$ external tempo.

given words (S). This ranking of task difficulty is based on Fraisse (1963). The stimuli were presented on white $6 \times 9 \mathrm{~cm}^{2}$ cards. For each task, 25 stimuli were presented. For the first task, the stimuli were Hebrew words. For the second, they were pictures of various objects whose names appear with the same frequency in Hebrew as the words for the first task. For the third task, the stimuli were Hebrew words whose frequency of occurrence was lower than those for the other two tasks.

\section{The Manipulation of External Tempo}

External tempo was manipulated in the following manner: (1) Visual "tempo"-A white light bulb was positioned $1 \mathrm{~m}$ away from the subject. This bulb could be either totally inactive or flickering at one of two frequencies: $0.5 \mathrm{sec}$ (fast) or $2 \mathrm{sec}$ (slow). (2) Auditory "tempo"-An electronic buzzer provided tones at the same two frequencies as above or not at all. In both visual and auditory "tempo," the stimulation was present during the entire target interval to be estimated.

\section{Method of Time Estimation}

The method used was one of reproduction within the frame of a prospective paradigm; that is, the subjects knew in advance that they would be required to estimate the duration of the interval during which they performed each task. The subjects were required to press a switch for a period of time subjectively equal to the length of time used to carry out the task. The press of the switch activated a hidden electronic timer from which the subjective time estimates (STE) could be recorded.

\section{Experimental Design}

The experimental design is presented in Table 1.

\section{Procedure}

The subjects were divided randomly into five groups: fast visual, fast auditory, slow visual, and slow auditory, with 16 subjects in each, and a control group with 32 subjects. Each subject was tested individually and provided four STEs for each of the four tasks. Order of presentation of tasks was counterbalanced. The objective time interval, which was $14 \mathrm{sec}$ for all tasks, was delineated by the experimenter saying "start" and "stop" with reference to an electronic timer. In each task, a pile of 25 cards was placed before the subject, who turned over each card in succession. The subjects were asked to perform each task as fast and as accurately as possible. In the condition of "empty" interval, the objective time interval was demarcated in the same manner by the experimenter. The subject, however, was not required to perform any task. The experimenter did not draw the attention of the subject to the external tempo, which was activated or not according to the experimental group to which the subject belonged. The subject was not required to do anything with regard to this external stimulation so that it would not appear to be relevant information. For each subject, both the STEs and the number of responses (e.g., cards) completed for each task were recorded.

\section{RESULTS}

Table 2 presents the mean STEs according to experimental groups and tasks. In order to test whether external tempo was modality specific, an ANOVA with three factors-task $\times$ tempo rate $\times$ modality (visual vs. auditory), with repeated measures for task-was conducted for groups exposed to external tempo. Significant main effects for tempo rate $[F(1,60)=13.81, p<.01]$ and task $[F(3,180)=$ $139.85, p<.01]$ were found. No effect for modality $[F(1,60)=.28]$ and no interactions were found. Hence, a two-way ANOVA (external tempo rate $x$ task), collapsed over modality and with the control group as a level in tempo rate and with repeated measures for the task factor, was conducted. Significant main effects for external tempo rate $[F(2,93)=7.01$, $\mathrm{p}<.01]$ and task $[\mathrm{F}(3,279)=197.58, \mathrm{p}<.01]$ were found, but no interaction. The trend of results is presented in Figure 1. Multiple comparisons were conducted by means of the Dunnett test, the results of which appear in Table 3 together with the respective comparisons of interest.

The mean number of responses are provided in Table 4, according to experimental groups and tasks.

Table 2

Mean STEs (in Seconds) and Standard Deviations According to Experimental Conditions

\begin{tabular}{|c|c|c|c|c|c|c|c|c|}
\hline \multirow[b]{3}{*}{ Modality } & \multicolumn{8}{|c|}{ Task } \\
\hline & \multicolumn{2}{|c|}{ w } & \multicolumn{2}{|c|}{$\mathbf{N}$} & \multicolumn{2}{|c|}{$\mathbf{S}$} & \multicolumn{2}{|c|}{ E } \\
\hline & STE & SD & STE & SD & STE & SD & STE & SD \\
\hline & \multicolumn{8}{|c|}{ Fast ETR } \\
\hline $\mathrm{v}$ & $10.27 *$ & 2.65 & $8.92 *$ & 2.11 & $8.52^{*}$ & 3.10 & $15.37^{*}$ & 3.36 \\
\hline $\mathrm{A}$ & $11.23^{*}$ & 3.47 & $9.72 *$ & 2.90 & $8.63^{*}$ & 3.10 & $15.06^{*}$ & 2.21 \\
\hline \multirow[t]{2}{*}{ Total } & $10.75 * *$ & 3.08 & $9.32 * *$ & 2.53 & $8.57 * *$ & 3.05 & $15.22 * *$ & 2.80 \\
\hline & \multicolumn{8}{|c|}{ Slow ETR } \\
\hline $\mathrm{v}$ & $8.81^{*}$ & 2.47 & $7.96^{*}$ & 1.94 & $7.31 *$ & 2.47 & $12.41^{*}$ & 1.33 \\
\hline A & $8.69 *$ & 1.74 & $7.62 *$ & 2.06 & $7.69 *$ & 1.89 & $12.97 *$ & 1.51 \\
\hline \multirow[t]{3}{*}{ Total } & $8.75 * *$ & 2.10 & $7.79 * *$ & 1.97 & $7.50^{* *}$ & 2.17 & $12.69^{* *}$ & 1.43 \\
\hline & \multicolumn{8}{|c|}{ Control } \\
\hline & $9.20 * *$ & 2.67 & $8.61^{* *}$ & 2.73 & $7.58^{* * *}$ & 3.06 & $13.60^{* *}$ & 2.10 \\
\hline
\end{tabular}

Note-ETR = external tempo rate $\boldsymbol{V}=$ visual modality; $A=$ auditory modality. $\quad *_{n}=16 . \quad *_{n}=32$. 


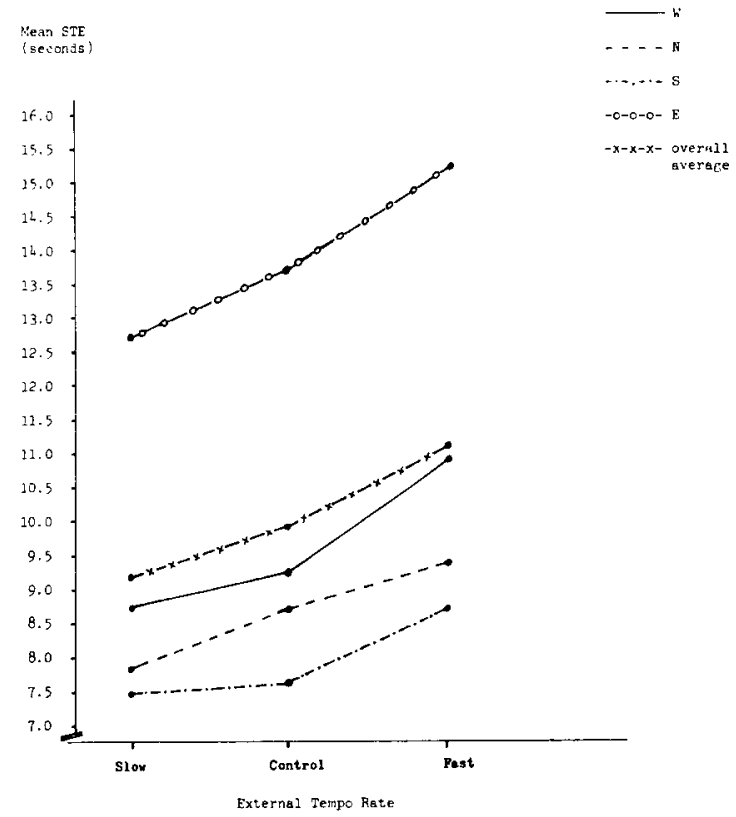

Figure 1. Mean STEs according to experimental conditions (collapsed over modality).

Table 3

Multiple Comparisons

\begin{tabular}{cccc}
\hline \multirow{2}{*}{$\begin{array}{c}\text { Experimental } \\
\text { Conditions }\end{array}$} & \multicolumn{2}{c}{ Comparison } & \\
\cline { 2 - 3 } & $\mathrm{M}_{1}$ & \multicolumn{1}{c}{$\mathrm{M}_{2}$} & Dunnett T \\
\hline FE-FS & 15.22 & 8.57 & $6.83^{*}$ \\
FE-FN & 15.22 & 9.32 & $6.06^{*}$ \\
FE-FW & 15.22 & 10.75 & $4.59^{*}$ \\
CE-CS & 13.60 & 7.58 & $6.18^{*}$ \\
CE-CN & 13.60 & 8.61 & $5.12^{*}$ \\
CE-CW & 13.60 & 9.20 & $4.52^{*}$ \\
SE-SS & 12.69 & 7.50 & $5.33^{*}$ \\
SE-SN & 12.69 & 7.79 & $5.03^{*}$ \\
SE-SW & 12.69 & 8.75 & $4.04^{*}$ \\
\hline
\end{tabular}

Note-Only significant compurisons are reported. $\quad * p<.01$ $(d f=11,84 ;$ one-tailed $)$.
An ANOVA in the former design, but without task $E$, revealed only a significant main effect for task $[F(2,186)=270.71, p<.01]$. In all experimental groups and under all conditions, number of responses decreased as task difficulty increased. A subsequent analysis for modality provided only a slight, nonsignificant, trend for more responses under auditory external tempo than under visual tempo. It should be noted that almost no errors were made and task difficulty was manifested through the number of responses only.

The relationship between number of responses and STE was further analyzed by means of Pearson correlations. Most of the correlations found were low and not significant, and the overall pattern revealed an inconsistent and nonsystematic relationship. The correlation coefficients are presented in Table 5 . The same pattern was obtained for each modality alone. Trend analysis was performed on STE. A significant linear trend $[F(1,93)=6.75, p<.05]$ was found for STEs in the E task, with the STEs in the order of slow external tempo, control, and fast external tempo. The same was true for the $W$ task $[F(1,93)=4.22$, $\mathrm{p}<.05]$. The quadratic trends were nonsignificant in both cases.

\section{DISCUSSION}

The findings obtained clearly indicate that STE is a negative function of task difficulty. This was true for all experimental groups and for all experimental tasks. In addition, "empty" intervals were consistently estimated to be of significantly longer duration than the "filled" intervals. This, again, was found with all experimental groups and tasks. Hence, on the basis of these two findings, the timer model is supported, but the storage-size model is refuted. As for the external tempo, it has been consistently found, for all experimental conditions, that STE is a monotonically increasing function of external tempo

Table 4

Mean Number of Responses and Standard Deviations According to Experimental Conditions

\begin{tabular}{|c|c|c|c|c|c|c|}
\hline \multirow[b]{3}{*}{ Modality } & \multicolumn{6}{|c|}{ Task } \\
\hline & \multicolumn{2}{|c|}{ W } & \multicolumn{2}{|c|}{$\mathbf{N}$} & \multicolumn{2}{|c|}{$\mathbf{S}$} \\
\hline & NR & SD & NR & SD & NR & SD \\
\hline & \multicolumn{6}{|c|}{ Fast ETR } \\
\hline $\begin{array}{l}\text { V } \\
\text { A } \\
\text { Total }\end{array}$ & $\begin{array}{l}10.87^{*} \\
11.44 * \\
11.16 * *\end{array}$ & $\begin{array}{l}2.12 \\
1.86 \\
1.98\end{array}$ & $\begin{array}{c}9.12 * \\
10.00^{*} \\
9.56 * *\end{array}$ & $\begin{array}{l}2.02 \\
1.59 \\
1.84\end{array}$ & $\begin{array}{l}5.94^{*} \\
6.50^{*} \\
6.21^{* *}\end{array}$ & $\begin{array}{l}1.98 \\
1.41 \\
1.71\end{array}$ \\
\hline Total & \multicolumn{6}{|c|}{ Slow ETR } \\
\hline $\begin{array}{l}\text { V } \\
\text { A } \\
\text { Total }\end{array}$ & $\begin{array}{l}10.31^{*} \\
11.25^{*} \\
10.78^{* *}\end{array}$ & $\begin{array}{l}1.81 \\
2.88 \\
2.41\end{array}$ & $\begin{array}{l}8.56^{*} \\
9.31^{*} \\
8.94^{* *}\end{array}$ & $\begin{array}{l}1.93 \\
2.49 \\
2.22\end{array}$ & $\begin{array}{l}5.62^{*} \\
6.50^{*} \\
6.06^{* *}\end{array}$ & $\begin{array}{l}1.40 \\
2.25 \\
1.89\end{array}$ \\
\hline \multirow{2}{*}{ Total } & \multicolumn{6}{|c|}{ Control } \\
\hline & $10.78 * *$ & 2.80 & $9.25 * *$ & 2.59 & $5.96^{* *}$ & 1.51 \\
\hline
\end{tabular}

Note-ETR $=$ external tempo rate; $V=$ visual modality; $A=$ auditory modality. $\quad *_{n}=16 . \quad *_{n} n=32$. 
Table 5

Pearson Correlations Between Number of Responses and Time Estimates $(n=32)$

\begin{tabular}{|c|c|c|c|c|c|c|}
\hline \multirow[b]{3}{*}{ Task } & \multicolumn{6}{|c|}{ External Tempo Rate } \\
\hline & \multicolumn{2}{|c|}{ Slow } & \multicolumn{2}{|c|}{ Control } & \multicolumn{2}{|c|}{ Fast } \\
\hline & $\mathrm{PC}$ & $\mathrm{p}=$ & PC & $p=$ & $\mathrm{PC}$ & $\mathrm{p}=$ \\
\hline W & 0.11 & .27 & -0.00 & .49 & -0.04 & .40 \\
\hline $\mathbf{N}$ & -0.13 & .22 & -0.40 & .01 & 0.07 & .33 \\
\hline $\mathbf{S}$ & 0.33 & .03 & -0.04 & .40 & 0.15 & .19 \\
\hline
\end{tabular}

Note $-P C=$ Pearson correlation.

rate, which indeed both models predict. However, according to the explanation provided by the storagesize model, one would expect that even slow external stimulation would add to the amount of information stored and that, hence, the STE would be longer in that instance than it would be for the control group with no external stimulation. Nevertheless, it was found consistently that STEs were shorter under slow-rate external tempo than in the control group. This is especially evident in the E task. Hence, it seems as if even the finding of a positive relationship between length of STE and external tempo rate is not consistent with the storage-size model. On the other hand, the trend found is well explained by the timer model, since it is plausible to assume that the slow external tempo was slower than the natural internal tempo of the timer, which caused the cognitive timer to slow down. A further result of interest is the lack of influence of external tempo rate on number of responses. If it were true that external stimulation was processed and added to storage, then, since it was found that response number decreased significantly as task difficulty increased, one would predict that the number of responses would decrease. Hence, it might be concluded that nonrelevant external stimulation was not increasing information-processing load. It should also be noted that no systematic relationship was found between the number of responses and STE. This relationship was dependent on experimental conditions, and even when it reached significance it explained, at most, only $16 \%$ of the variance. This indicates that the relationship between number of responses and STE is not a direct one but is mediated through task difficulty. Thus, on the basis of all the findings, it can be concluded that all the predictions stemming from the timer model were supported in a consistent way, while the opposite was the case in regard to the storage-size model. However, one cannot totally reject the storage-size model on the basis of the present study, since it was restricted to a specific task, duration, and time-estimation methodology. In light of the findings of Allan (1979) and Hicks et al. (1976, 1977), who stress the influence of methodology on time perception, the research should continue, with all of the relevant experimental variables being varied in a systematic and controlled fashion. It might be found that the storage-size model is the correct one under a specific combination of experimental conditions. The conclusions that are possible to draw here are that support is lent to the timer concept within a prospective paradigm of time estimation by a reproduction method for durations of about $14 \mathrm{sec}$ and for tasks similar to those used in the present study. In this respect, the model introduced by Thomas and Weaver (1975) is relevant here. According to that model, each stimulus is analyzed by two processors: (1) a timer, $\mathbf{P ( t )}$, which processes temporal information, and (2) a nontemporal information processor, $P(I)$. Attention is divided between $P(t)$ and $P(I)$ according to the nature of the task and the attentional load demanded for its performance. Time estimation is a function based on the two processors, with the contribution of each being proportional to the amount of attention allocated to it. According to Thomas and Weaver's (1975) model, judged duration increases with processing load. However, as Allan (1979) noted, thus far the application of the model has been restricted to $\mathrm{d}<100 \mathrm{msec}$. The following elaboration of the model is suggested here:

$$
\text { Time estimation }=f\{\gamma[\mathrm{P}(\mathrm{t})] ; \beta[\mathrm{P}(\mathrm{I})]\} ; \gamma+\beta=1 \text {, }
$$

where $\gamma$ and $\beta$ are importance weights attached to the information obtained from the two processors after the information processing itself has been terminated. These importance weights are influenced not only by attentional demands, but also by other factors, such as estimation paradigm (e.g., absolute or comparative), interval duration, etc. As for interval duration, it is plausible to assume that, for very short durations, $\gamma$ is very small, since the timer is not effective, but that when the duration becomes long, $\gamma$ becomes higher. This might explain the discrepancy between the prediction of the Thomas et al. model for short durations and the results obtained in this study for longer durations.

The results obtained here also support the assumption that the timer works according to some internal tempo which might be speeded up or slowed down, depending on the external tempo. However, in light of the unclear and controversial empirical findings obtained so far, that assumption must be subjected to further empirical research, with external tempo varied so that the pattern of its relationship with STE can be determined on the basis of many points along the continuum of tempo rather than on the basis of only three. The mechanism by which external tempo might influence the timer is not understood. One assumption that might be made here is that this mechanism is central rather than modality specific. This assumption is based on the lack of significant effects of modality on STE, as found here and as supported by a number of empirical findings, which are sum- 
merized by Allan (1979, p. 347). Indeed, a slight, nonsignificant, trend for more responses under auditory tempo than under visual tempo was noted, but this is interpreted here as an artifact of the experimental conditions, as one does not have to pay attention to an auditory external tempo in order for that source to influence the timer. In contradistinction, a visual source will be effective only if the subject pays attention to it by looking, during which rate of response is inevitably reduced. One possible mechanism is that of arousal (Curton \& Lordahl, 1974). This interesting question, however, should also be the subject of future research.

\section{REFERENCES}

Aitken, R. C. B., \& Gedye, J. L. A study of two factors which affect arousal level and the apparent duration of a ten-minute interval. British Journal of Psychology, 1968, 59, 253-263.

Allan, L. G. The perception of time. Perception \& Psychophysics, 1979, 26, 340-354.

Avant, L. L., Lyman, P. J., \& Antes, J. Effect of stimulus familiarity upon judged visual duration. Perception \& Psychophysics, 1975, 17, 253-262.

BLock, R. A. Remembered duration: Effects of event and sequence complexity. Memory and Cognition, 1978, 6, 320-326.

Burnside, $W$. Judgment of short time intervals while performing mathematical tasks. Perception \& Psychophysics, 1971, 9, 404-406.

Curton, E. D., \& Lordahl, D. S. Attentional focus and arousal in time estimation. Journal of Experimental Psychology, 1974, $103,861-867$.

Denner, B., Wapner, S., McFarland, J., \& Werner, H. Rhythmic activity and the perception of time. American Journal of Psychology, 1963, 76, 287-292.

Devane, J. R. Word characteristics and judged duration for two response sequences. Perceptual \& Motor Skills, 1974, 38, 525-526.

Fraisse, P. The psychology of time. New York: Harper \& Row, 1963.

Frankenhauser, M. Estimation of time. Stockholm: Almquist \& Wiksell, 1959.

Gulliksen, H. The influence of occupation upon the percep- tion of time. Journal of Experimental Psychology, 1927, 10, 52-59.

HAwkes, G. R., BAILEY, R. W., \& WARM, J. S. Method and modality in judgments of brief stimulus duration. Journal of Auditory Research, 1961, 2, 133-144.

Hawkes, G. R., Joy, R. J. T., \& Evans, W. O. Autonomic effects on estimates of time: Evidence for a physiological correlate of temporal experience. Journal of Psychology, 1962, 53, 183-191.

Hawkes, G. R., \& Worsham, W. Time perception for helicopter vibration and noise patterns. Journal of Psychology, 1970, 76, 71-77.

Hicks, E. R., Miller, G. W., Gaes, G., \& Bierman, K. Concurrent processing demands and the experience of time in passing. American Journal of Psychology, 1977, 90, 431-446.

Hicks, E. R., Millen, G. W., \& Kinsbounne, M. Prospective and retrospective judgments of time as a function of amount of information processes. American Journal of Psychology, 1976, 89, 719-730.

Hongland, H. Pacemakers in relation to aspects of behavior. New York: Macmillan, 1935.

Lyman, P. J., \& Avant, L. L. Stimulus familiarity modifies perceived duration in precognition visual processing. Journal of Experimental Psychology, 1975, 104, 205-219.

McKay, G. E., \& TiмотнY, D. Time estimation: Effects of attentional focus and of a comparison of internal conditions. Perception \& Motor Skills, 1977, 45, 584-586.

Michon, J. A. Studies on subjective duration: Subjective time measurement during tasks with different information content. Acta Psychologica, 1965, 24, 205-219.

Ornstein, R. E. On the experience of time. Middlesex, England: Penguin, 1969.

Priestly, J. B. Man and time. New York: Dell, 1968.

Schiffman, H. R. Sensation and perception: An integrated approach. New York: Wiley, 1976.

SwifT, E. Y., \& McGough, J. A. An experimental study of the perception of filled and empty time. Journal of Experimental Psychology, 1925, 8, 240-249.

Thomas, E. A. C., \& Weaver, W. B. Cognitive processing and time perception. Perception \& Psychophysics, 1975, 17, 363-367.

VRoon, P. A. Effects of presented and processed information on duration experience. Acta Psychologica, 1970, 34, 115-121.

ZAKAY, D., \& Fallach, E. Immediate and remote time estimation-a comparison. Acta Psychologica, in press.

(Manuscript received March 28, 1983; revision accepted for publication July 25,1983 .) 